\title{
Ampliar y profundizar horizontes a través de la formación humanista
}

Adriana Alfieri Casalegno

Una inquietud

A

finales de 2011 estuvo en nuestra institución la doctora Teresa Kwiatkowska, profesora de la Universidad Autónoma Metropolitana, especialista en el tema de la ética ambiental y autora de varios libros y artículos relacionados con esta temática. Durante una conferencia ofrecida por la doctora, un alumno hizo una pregunta significativa: ¿Por qué la universidad sigue formando profesionales tecnológicamente muy capaces, pero ajenos a la responsabilidad humana de preservación y cuidado del medio ambiente?

Evidentemente, no es posible saber si ésta es una inquietud generalizada entre los estudiantes, pero sí lo es el hecho de que resulte impensable disminuir el interés por el conocimiento científico-tecnológico y por el desarrollo de las habilidades necesarias en la construcción y uso de todo tipo de tecnología.

Nuestra institución no es ajena a ninguna de estas cuestiones, por lo que ha comenzado a implementar cursos relativos a la temática ambiental, mismos que se han unido a los que conforman la orientación de la formación humanista de la UAA. Así, aun cuando la inquietud de ese joven estudiante pudiera manifestar un escaso conocimiento de lo que sucede en su casa de estudios, puede servir de base para considerar al menos tres cosas: a) la importancia de la formación humanista en el contexto de una formación profesional integral u holística; b) la posibilidad de que aún haya algunas cuestiones relevantes que no se estén considerando en la formación universitaria que desea reunir estas cualidades; y c) la necesidad de convertir el concepto de formación integral en una filosofía de vida académica, en una forma de ser universitario y en un modelo de actuación institucional, de tal manera que la formación integral no se traduzca en cursos más o menos marginales -o no solamente en ellos- sino que esté presente en todos los cursos y en todas las carreras que ofrece la máxima casa de estudios.

\section{La formación humanista desde una perspectiva filosófica}

La filosofía es una fuente privilegiada de conocimiento que, en conjunción con las aportaciones de otras disciplinas, puede contribuir a la conformación de esta realidad - primero de forma conceptual y, posteriormente, acompañando la implementación y evaluación de las acciones emprendidas para llevar las ideas y las intenciones al terreno de los hechos. 
Hans-Georg Gadamer ${ }^{1}$ denuncia el hecho de que a partir de la Ilustración y hasta el siglo xx hay un interés desmedido por la ciencia - una especie de idolatría-, con la consecuente primacía del método científico sobre cualquiera otra forma de acercamiento a la realidad y, aunado a esto, el desprecio o descrédito de las ciencias humanas.

Gadamer se rebela contra esta situación en su obra Verdad y método, ${ }^{2}$ intentando recuperar y actualizar el humanismo, rescatar y poner en evidencia la importancia de las ciencias humanas, y deslindar los hechos y los métodos propios de estas ciencias de los que pertenecen a las ciencias naturales.

En estas líneas no se pretende señalar el camino teórico seguido por Gadamer en su crítica a la visión cientificista del mundo, sino retomar algunos conceptos a los que recurre y con los que explica y logra establecer sus propuestas humanistas. Primero, el concepto de formación, que en algún momento se concibió como un ascenso o llegar a ser humano, y que no es sólo "el modo específicamente humano de dar forma a las disposiciones y capacidades naturales del hombre", sino que implica el desarrollo de la conciencia -como ese sentido en el que se muestran la racionalidad y la espiritualidad humana, el sentido humano que trasciende lo inmediato y natural, un sentido que se caracteriza por mantenerse abierto, operar en todas direcciones y ser capaz de discernir.

Otro concepto importante es el de sentido común (sensus communis), que no ha de ser entendido como una real o supuesta capacidad humana generalizada de pensar y actuar razonablemente -algo importante a lo que contribuye la formación universitaria-, sino como la connotación de sentido comunitario que tenía en la tradición humanista, la base sobre la que se funda la comunidad, el sentido de lo justo y del bien común que vive -se pensaba entoncesen todos los hombres, un sentido que nace y se desarrolla, precisamente, dentro de la comunidad, a través de los objetivos y la forma de vida compartidos por sus miembros. El sentido común, así entendido, significa también amor a la comunidad o a la sociedad, afecto o cariño natural, humanidad y compromiso. Utilizando palabras actuales, es el sentido de pertenencia a la comunidad, el cultivo de un interés (inter esse, lo que está entre), lo que está entre dos distintas vivencias subjetivas (entre la necesidad y la valoración del individuo), entre las necesidades y valoraciones de dos sujetos que se relacionan, entre las del individuo y la colectividad (presente o futura).

Lo dicho facilita comprender por qué el concepto de sensus communis es central en el humanismo, por qué se le atribuye una importancia decisiva para la vida. Formarlo, desarrollarlo es, por lo tanto, la finalidad suprema de la educación. Y aquí es necesario mencionar que el sentido común implica, además de lo dicho, las nociones de decir lo correcto y verdadero, es decir, las cualidades atribuidas al
Destacado filósofo alemán (1900 2002) considerado el padre de la Neohermenéutica, una teoría filosófica que hace de la interpretación y la comprensión el tema central, un problema ontológico y universal. Obra magna de Gadamer, publicada en 1960 y ampliada por un segundo volumen en 1986. 
sabio, razón por la que los conceptos tradicionales de prudentia y eloquentia (saber actuar y saber decir la verdad o decir con verdad) son elementos indispensables. Con el lenguaje de hoy, podríamos decir que la formación humanista deberá propiciar que se mantengan actitudes, actuación y comunicación acertadas, sensatas, libres (asertivas, proactivas, resilientes, entre otras), es decir, sabias.

\section{El momento actual}

Considerando ahora dos rasgos humanos bien conocidos: el cambio en la forma de ser y vivir, y los particulares intereses de la época, se puede afirmar que la situación de la humanidad presente, particularmente de la mayoría de las personas en nuestro país, no es ya la de una cua$s i$ devoción a la ciencia y al método científico, sino a la tecnología -que se construye con las aportaciones científicas y que se renueva con asombrosa rapidez-, y a cuestiones de índole económico-financiera -la avidez por conseguir un patrimonio considerable y una buena posición económica, preferiblemente de manera rápida y sin demasiado esfuerzo.

Dejando de lado otras cuestiones que entusiasman a la gente (que con gusto se somete a su dominio y tiranía), vale resaltar algunos efectos de los apuntados tecnología y dinero. Pocos se atreverían hoy en día a negar la utilidad de estos factores en la vida humana: son herramientas poderosas, medios maravillosos para acceder a un sinnúmero de bienes, llaves maestras para abrir infinidad de nichos de oportunidad. Pero no todo son ventajas con la tecnología y con el dinero; en gran parte porque han dejado de considerarse medios y se han constituido en fines, porque se les ha dejado de ver como instrumentos o herramientas capaces de favorecer las relaciones interpersonales, el bienestar colectivo de los grupos humanos y de los individuos concretos que los integran, para convertirse en los fines del deseo y de la satisfacción subjetivos, la imaginaria fuente de un bienestar individual e individualista producto de una visión de muy corto alcance, todo lo cual ha provocado, según se ha estudiado y denunciado ampliamente, serios problemas en la comunicación humana, en el sentido de comunidad y en el impacto ambiental de la actividad humana.
Los jóvenes universitarios están inmersos en este mundo de intereses, creencias y tendencias, en él han nacido y crecido, en él se desenvuelven y en él se va conformando su personalidad. Ya que la juventud es un estado que no contribuye a comprender plenamente las implicaciones y la trascendencia de esta dinámica, es necesario que las instituciones educativas apoyen a los jóvenes en su proceso de maduración (algunas situaciones hacen pensar que hoy se considera que prolongar indefinidamente la niñez es un derecho de los jóvenes). Ir alcanzando mayor madurez (mayor sabiduría) significa ampliar el horizonte de la conciencia -en extensión y en profundidad-, ser más objetivos y críticos, responsabilizarse de las decisiones tomadas, salir del egoísmo y del egocentrismo, contextualizar y relativizar, comprender y desarrollar la condición de seres sociales -que requiere del otro para dar y recibir no sólo prestaciones y contraprestaciones sino, y sobre todo, humanidad y comunidad-, apropiarse de lo que a cada uno lo va constituyendo como persona, así como de la persona en la que se va conformando, aprender a comunicarse (contrariamente a lo que algunos piensan, no se puede decir que alguien sabe comunicarse sólo porque domina el manejo de la amplia gama disponible de tecnologías de información y comunicación), comunicar la verdad, conocer y comunicar la propia verdad -en la forma más oportuna en cada caso: atendiendo, escuchando, interesándose y comprendiendo al interlocutor, al mismo tiempo que se intenta ser escuchado y comprendido. Abreviando, construir el propio ser y la propia vida a través de una actuación digna y dignificante.

\section{Conclusión}

A pesar de la brevedad con la que se han descrito estas ideas, no es difícil reconocer que corresponden al contenido y a las consecuencias de los conceptos retomados por Gadamer. Esto es crucial ya que, como el mismo autor afirma, los profesionales han de dedicarse a actividades que no realizarían para sí mismos, es decir, a cubrir necesidades que en primera instancia ellos no tienen, y que sólo comprendiéndolas y sintiéndolas como propias les dará la motivación necesaria para combatirlas, en un afán de proporcionar bienestar a quienes les han brindado su confianza. Pero no sólo eso -y aquí 


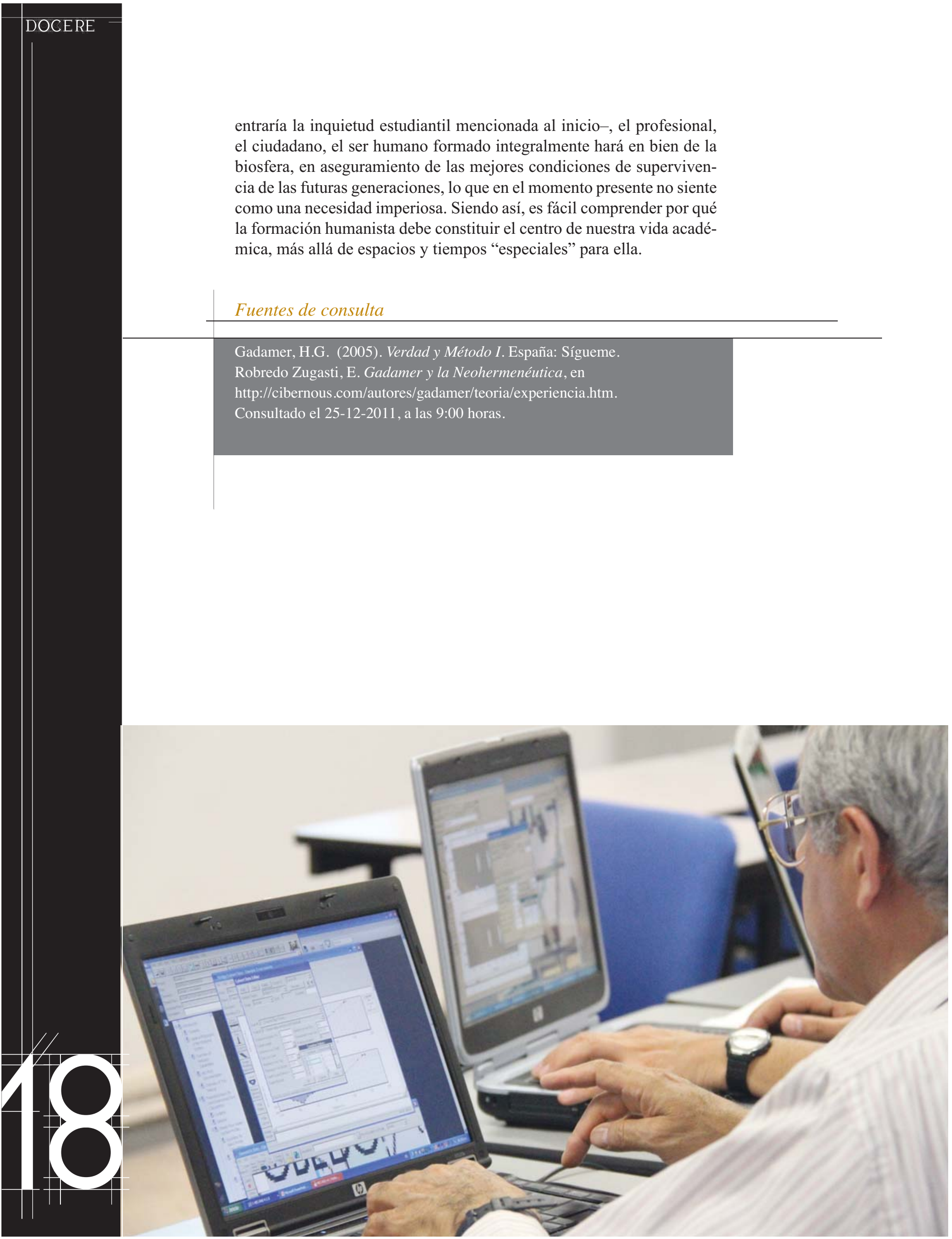

